\title{
Studies on Mechanical, Thermal, Electrical Properties and Accelerated UV Weathering of PP with HIPS Blends
}

\author{
S Soundararajan* and K Palanivelu \\ Dept of Plastics Technology/Central Institute of Plastics Engineering and Technology \\ Guindy, Chennai-600 032 , India
}

\begin{abstract}
Poly Propylene (PP) was blended with High impact poly styrene (HIPS) (10-25\%) using a twin screw extruder. Then the test specimens were prepared using an injection molding machine and testings were done as per ASTM standards. The mechanical properties like Tensile modulus, Flexural strength and Flexural modulus were increased. The impact strength, Tensile strength and elongation were decreased. In the thermal properties HDT was improved because HIPS has higher properties than that of PP. The Arc resistance was little lowered. The shrinkage was decreased. Accelerated UV Weathering was also carried out using an accelerated weather-o-meter. The PP-HIPS blends were found to be photo-degradable after 125 hours of UV light exposure in accelerated Weather-o-meter and in about 2.5 months in the out-door exposure.
\end{abstract}

Key words: PP- HIPS Blends, Mechanical, Thermal, Electrical properties, SEM, and Accelerated UV Weathering.

\section{Introduction}

PP (Poly Propylene) is similar to HDPE but also differs from HDPE in the following aspects that it has high brittleness point. But it has higher VSP (Vicat softening point), hence higher service temperature than HDPE. Applications of PP are as follows: Sterilizable equipments, luggage, stacking chair, washing machine parts, carpets, dome lights, door fame parts[1]. Elastomer EPDM modified blends or copolymers of EPR, as car battery cases, car bumpers [2]. PP also useful as flower pots, straps, ropes \& nets [1].

HIPS a high impact polystyrene (Polystyrene-SBR Blend), with 5-10\% Polybutadiene, has lower hardness \& softening point,and has seven times higher impact strength then that of PS (Poly styrene) [3] because of the rubber content there is a reduction of heat stability and light stability [3] and are useful in disposable applications like cups, plates, trays, pens and electrical \& electronic housings such as Radio, TV cabinets.

Also Poly propylene has higher shrinkage leading to sink marks due to crystalline nature of the polypropylene. Hence, the high impact poly styrene will reduce the sink marks and shrinkage in the polymer alloys and blends of PP-HIPS and uniform thickness can be obtained in the plastics products. Also photodegradability of the HIPS can be incorporated in to the PP products. HIPS is widely used in disposable plastic application like disposable pens, cups, trays. PP Products like PP film bags, sheets and packaging containers blended with HIPS will be easily photo-degradable in presence ultra violet (UV) light of sun light. In the previous study we have reported Accelerated UV weathering of HIPS blended with Starch (4). Also we have reported the mechanical, thermal and electrical properties of sugarcane waste filled HIPS (5). In this present study the PP is melt blended and then the mechanical, thermal and electrical properties were evaluated. The photo- degradability of PP-HIPS(10-25 wt\%) blends are also evaluated.

\subsection{Raw Materials}

\section{Experimental}

PP is obtained from Reliance petrochemicals limited. The trade name is Royalene. The HIPS is obtained from a plastics industry. PP is injection grade (MFI $8 \mathrm{gm} / 10 \mathrm{~min}$ ). HIPS is extrusion grade (MFI in 6 $.7 \mathrm{gm} / 10 \mathrm{~min})$.

\subsection{Compounding}

The PP and HIPS granules were mixed thoroughly in a high speed mixer and then compounded in a twin screw extruder (Berstorff, FRG).The temperature range used was $110-205^{\circ} \mathrm{C}$. The extrudate was passed through a water cooling trough and then cut into granules. The screw rpm was about 50-60 rpm.

\subsection{Testing}

The test specimens were prepared using an injection molding machine (SP130 Klocknar Windsor) using temperature range of $160-210{ }^{\circ} \mathrm{C}$ and injection pressure about 15000 PSI. The testings were done as per ASTM Standards [6]. 


\subsection{Scanning Electron Microscopy.}

For PP and PP-HIPS blend (10 \& $25 \mathrm{wt} \%)$ SEM micro photographs were taken at Material science department, IIT, Chennai at 1000 magnifications the SEMs were taken.

\subsection{Mechanical, thermal and electrical Properties}

\section{Results And Discussion}

The test results are given in the Tables $1,2,3 \& 4$. The mechanical properties were given in Table 1.The thermal and electrical \& physical properties were shown in Table 2 and 3 respectively..

The tensile strength of PP-HIPS blends were slightly decreased even though the HIPS has higher tensile strength than that of PP. But, the flexural strength and flexural modulus were increased in both formulations. The elongation at break lowers. The tensile modulus increase as the HIPS content increases. The izod \& charphy notched impact strength decreases.since HIPS has lower impact strength than that of PP (Table $1)$.

The VSP (Vicat softening point) was decreasing (Table 2). Because HIPS has Poly butadiene and also the $\mathrm{Tg}$ (Glass Transition Temperature) of Poly styrene units is in the range 100-105 ${ }^{\circ} \mathrm{C}$. The HDT was increased for both formulations. The HDT values of HIPS \& PP are lower than that of the blends. This shows that the blends may be compatible and synergistic effect is obtained in the HDT values. The MFI was similar to HIPS for formulation1; but slightly higher value was obtained for formulation 2.

Table 1. Mechanical Properties of PP-HIPS Blends

\begin{tabular}{|c|c|c|c|c|c|c|}
\hline SI No & Properties & Unit & PP & $\begin{array}{c}\text { 90:10 \% of PP- } \\
\text { HIPS }\end{array}$ & $\begin{array}{c}75: 25 \% \text { of PP- } \\
\text { HIPS }\end{array}$ & HIPS \\
\hline 1 & Tensile strength & $\mathrm{Kg} / \mathrm{Sq} \mathrm{cm}$ & 233 & 230 & 206 & 278 \\
\hline 2 & Elongation at break & $\%$ & 525 & 44 & 14.6 & 36.7 \\
\hline 3 & Tensile modulus & $\mathrm{Kg} / \mathrm{Sqcm}$ & 11220 & 12103 & 12395 & 22703 \\
\hline 4 & $\begin{array}{l}\text { Izod impact strength, } \\
\text { notched }\end{array}$ & $\mathrm{Kgcm} / \mathrm{cm}$ & 21.4 & 17.3 & 14.6 & 12.4 \\
\hline 5 & $\begin{array}{l}\text { Charpy Impact strength, } \\
\text { notched }\end{array}$ & $\begin{array}{l}\mathrm{Kg} \mathrm{cm} / \mathrm{sq} \\
\mathrm{cm}\end{array}$ & 17.3 & 9.5 & 5.9 & 6.7 \\
\hline 6 & Flexural strength & $\mathrm{Kg} / \mathrm{Sq} \mathrm{cm}$ & 192 & 228 & 244 & 295 \\
\hline 7 & Flexural Modulus & $\mathrm{Kg} / \mathrm{Sq} \mathrm{cm}$ & 5475 & 7016 & 7439 & 11554 \\
\hline
\end{tabular}

The electrical properties like volume resistivity and surface resistivity are lowered. Arc resistance was slightly decreasing since HIPS was having lower Are resistance (Table 3). The low arc resistance may be due to the unsaturated double bonds present in the Poly butadiene of HIPS, due to more electrical conductivity the arc resistance is lower. Also, the water absorption is increasing as the HIPS content was increasing.

The shrinkage was decreasing since HIPS is amorphous and has lower shrinkage PP is highly crystalline and has higher shrinkage. The density was increasing since HIPS has higher density than that of PP.

Table 2. Thermal Properties of PP-HIPS blends

\begin{tabular}{|c|c|c|c|c|c|c|}
\hline SI No & Properties & Unit & PP & $\begin{array}{c}\text { 90:10 \% of PP- } \\
\text { HIPS }\end{array}$ & $\begin{array}{c}\text { 75:25\% of PP- } \\
\text { HIPS }\end{array}$ & HIPS \\
\hline 1 & $\begin{array}{c}\text { Melt flow index } \\
\text { at } 230{ }^{\circ} \mathrm{C} / 2.16 \\
\mathrm{~kg}\end{array}$ & $\mathrm{Gm} / 10 \mathrm{~min}$ & 8 & 6.5 & 9.5 & 6.7 \\
\hline 2 & $\begin{array}{c}\text { Vicat softening } \\
\text { point }\end{array}$ & ${ }^{\circ} \mathrm{C}$ & 148.8 & 138.8 & 132.5 & 101.8 \\
\hline 3 & $\begin{array}{c}\text { Heat deflection } \\
\text { temp at 66 PSI }\end{array}$ & ${ }^{\circ} \mathrm{C}$ & 84 & 90 & 97.5 & 87 \\
\hline
\end{tabular}

\subsection{SEM Analysis}

The compatibility of the PP-HIPS blends were determined using a scanning electron microscope.(Fig 1-2).The SEM Photographs show that the PP-HIPS polymer molecules are not uniformly present in the blends and hence the PP- HIPS will be semi-compatible with each other at lower concentrations of HIPS. The SEM also contains some broken pieces of the PP \& PP-HIPS blends. The rubber particles are not visible due to Poly butadine units, the polymer may have good interfacial adhesive characteristic and so the polymer are partly compatible. The SEM of HIPS \& HIPS blends with HDPE, is reported in the literature [7]. 
Due to the semi- compatibility of PP-HIPS, There is a uniform change in the mechanical properties like tensile strength, elongation at break, tensile modulus, flexural modulus, impact strength were obtained. Higher HDT values were obtained.due to partial compatibility The compatibility may be improved by the use of compatibilizers like SEBS, SMA.

Table 3. Electrical and physical properties of PP-HIPS blends

\begin{tabular}{|c|c|c|c|c|c|c|}
\hline SI No & Properties & Unit & PP & $\begin{array}{c}\mathbf{9 0 : 1 0} \% \text { of PP- } \\
\text { HIPS }\end{array}$ & $\begin{array}{c}\mathbf{7 5 : 2 5 \%} \text { of PP- } \\
\text { HIPS }\end{array}$ & HIPS \\
\hline 1 & Arc resistance & Sec & 185 & 175 & 155 & 141 \\
\hline 2 & $\begin{array}{c}\text { Volume } \\
\text { Resistivity }\end{array}$ & $\begin{array}{c}\text { Ohm-cm } \\
\mathrm{x} \mathrm{E}+15\end{array}$ & 28.3 & 23.5 & 17.5 & 12 \\
\hline 3 & $\begin{array}{c}\text { Surface } \\
\text { resistivity }\end{array}$ & $\begin{array}{c}\text { Ohms } \\
\mathrm{x} \mathrm{E}+15\end{array}$ & 14.9 & 7.8 & 7 & 6.2 \\
\hline 4 & $\begin{array}{c}\text { Water absorption } \\
23^{\circ} \mathrm{C} / 24 \mathrm{hrs}\end{array}$ & $\%$ & 0.02 & 0.022 & 0.024 & 0.035 \\
\hline 5 & Density & $\mathrm{Gm} / \mathrm{cc}$ & 0.90 & 0.91 & 0.93 & 1.03 \\
\hline 6 & Shrinkage & $\%$ & 0.35 & 0.28 & 0.25 & 0.21 \\
\hline
\end{tabular}

\subsection{UV weathering for Photo degradation}

The photo degradation of PP-HIPS blends \&HIPS were studied using an accelerated weather-ometer at 0.53 watts for $125 \mathrm{hrs}$. The HIPS is photodegradable due to the unsaturated double bonds and hence makes the PP -HIPS blends photodegradable. Higher the HIPS content, lower the tensile strength \& elongation after UU weathering i.e the PP-HIPS more quickly degradable if HIPS concentration is more (25\%) and so the tensile strength \& elongation decreases more than that of PP-HIPS blends containing lower concentration(10\%) (Table 4). The photo-degradation of PP is due propagation of depolymerization initiated from HIPS polymer radical by Hydrogen abstracting mechanism. Due to photo-degradablity, the PP-HIPS plastic protucts will be photo-degradable in the outdoor in about 2.5 months time. The photodegradable plastic products will be then bio-degradable completely and hence eco-friendly can be made from the PPHIPS blends.

Table 4. Tensile strength and Elongation at break Before and after UV Accelerated weathering

\begin{tabular}{|c|c|c|c|c|c|c|}
\hline SI No & Properties & Unit & PP & $\begin{array}{l}\text { 90:10\% of } \\
\text { PP-HIPS }\end{array}$ & $\begin{array}{c}75: 25 \% \text { of PP- } \\
\text { HIPS }\end{array}$ & HIPS \\
\hline 1 & $\begin{array}{l}\text { Tensile strength } \\
\text { Before UV }\end{array}$ & $\mathrm{Kg} / \mathrm{Sq} \mathrm{cm}$ & 233 & 230 & 206 & 278 \\
\hline 2 & After UV & $\mathrm{Kg} / \mathrm{Sq} \mathrm{cm}$ & 267 & 223 & 190 & 284 \\
\hline 3 & $\begin{array}{c}\text { Elongation at } \\
\text { break } \\
\text { Before UV }\end{array}$ & $\%$ & 525 & 44 & 14.6 & 36.7 \\
\hline 4 & After UV & $\%$ & 51 & 20 & 10 & 40 \\
\hline
\end{tabular}

UV Weathering Conditions: As per ISO 4892 Standard.

Lamp source :60 Watt with Turning mode. Phase 1: 102 min (UV), Phase 2: 18 min(Rain)

Total Energy: $26625 \mathrm{Kj} / \mathrm{Sq} \mathrm{m}$.

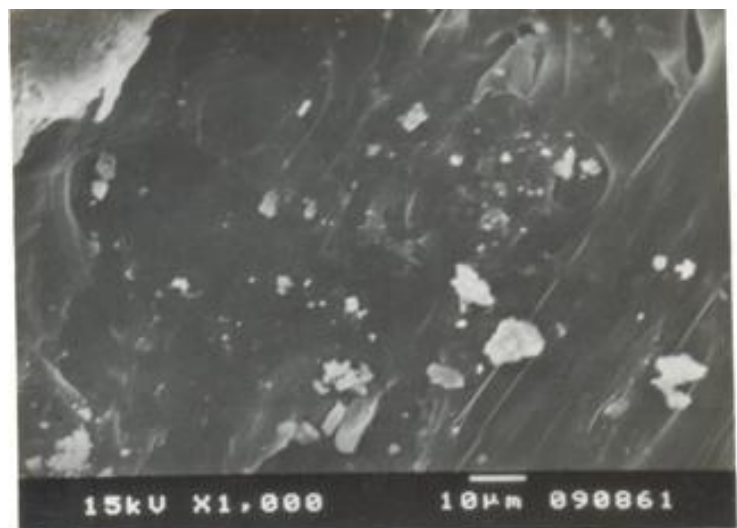

Figure 1. SEM of PP-HIPS Blend (90: 10\%) 


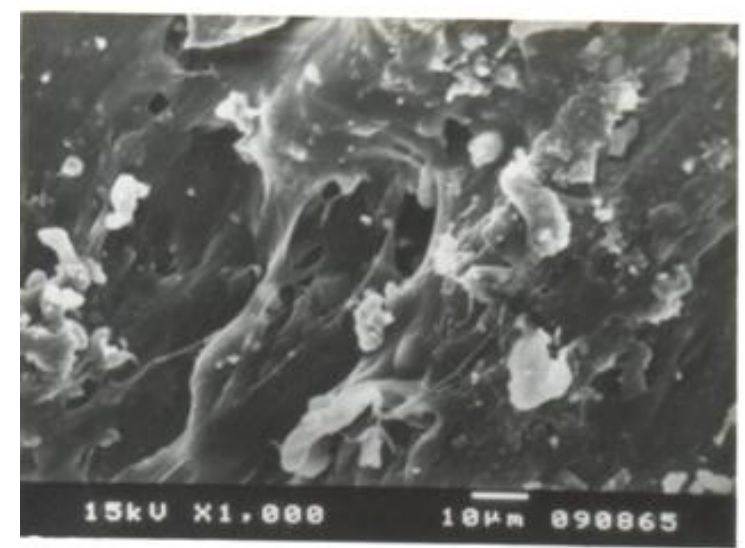

Figure 2 SEM of PP-HIPS Blend ( 75: 25\%)

\section{Conclusion}

The mechanical properties like Tensile modulus, Flexural strength and Flexural modulus were increased. The impact strength, Tensile strength and elongation were decreased. In the thermal properties HDT was improved because HIPS has higher properties than that of PP. The Arc resistance was little lowered. The shrinkage was decreased.

Accelerated weathering was also carried out using an accelerated weather-o-meter. The PP-HIPS blends were found to be photo-degradable after 125 hours of UV light exposure in accelerated Weather-o-meter and in about 2.5 months in the out-door exposure.

PP is widely used in carry bags and many other applications. The PP is light weight, low cost and chemical resistance. HIPS is widely used as disposable applications. PP -HIPS blends will be useful in electrical and electronic applications like Radio, TV, PC housings. In future a lot of e -waste will be generated. Hence the PP-HIPS blends will be Photo and Bio-Degradable.

\section{References}

[1]. J A Brydson, "Plastics Materials", Butter worth Heinnmann, Oxford 1990 \& $7^{\text {th }}$ Edition , P 266

[2]. R Rosalind, Modern Plastics encyclopedia-mid October issue, 1990

[3]. As ref 1 p 437

[4]. J Subburaj and S Soundararajan, IOSR-J. Applied Chemistry, Vol 1(2), 2012, P01-09

[5]. S Soundararajan, K Palanivelu and S K Sharma, IOSR-J. Polymer and Textile Engineering, Vol, 1(1), 2013, P01-03

[6]. Annual ASTM standards Vol. 08.01-0.4 2000, USA

[7]. H F Mark, Bikales, N.M., Overberger, C.G., Menges, G, “ Encyclopedia of Polymer Science and Engineering” John wiley \& science Publishers, $2^{\text {nd }}$ Edition, 1985, Vol. 12, P 421 